\title{
Gut microbiota in children with type 1 diabetes differs from that in healthy children: a case-control study
}

\author{
Mora Murri ${ }^{1 \dagger}$, Isabel Leiva ${ }^{2 \dagger}$, Juan Miguel Gomez-Zumaquero ${ }^{3}$, Francisco J Tinahones ${ }^{4,7}$, Fernando Cardona ${ }^{1,4}$, \\ Federico Soriguer ${ }^{5,6}$ and María Isabel Queipo-Ortuño $0^{1,4^{*}}$
}

\begin{abstract}
Background: A recent study using a rat model found significant differences at the time of diabetes onset in the bacterial communities responsible for type 1 diabetes modulation. We hypothesized that type 1 diabetes in humans could also be linked to a specific gut microbiota. Our aim was to quantify and evaluate the difference in the composition of gut microbiota between children with type 1 diabetes and healthy children and to determine the possible relationship of the gut microbiota of children with type 1 diabetes with the glycemic level.

Methods: A case-control study was carried out with 16 children with type 1 diabetes and 16 healthy children. The fecal bacteria composition was investigated by polymerase chain reaction-denaturing gradient gel electrophoresis and real-time quantitative polymerase chain reaction.

Results: The mean similarity index was $\mathbf{4 7 . 3 9 \%}$ for the healthy children and $37.56 \%$ for the children with diabetes, whereas the intergroup similarity index was $26.69 \%$. In the children with diabetes, the bacterial number of Actinobacteria and Firmicutes, and the Firmicutes to Bacteroidetes ratio were all significantly decreased, with the quantity of Bacteroidetes significantly increased with respect to healthy children. At the genus level, we found a significant increase in the number of Clostridium, Bacteroides and Veillonella and a significant decrease in the number of Lactobacillus, Bifidobacterium, Blautia coccoides/Eubacterium rectale group and Prevotella in the children with diabetes. We also found that the number of Bifidobacterium and Lactobacillus, and the Firmicutes to Bacteroidetes ratio correlated negatively and significantly with the plasma glucose level while the quantity of Clostridium correlated positively and significantly with the plasma glucose level in the diabetes group.

Conclusions: This is the first study showing that type 1 diabetes is associated with compositional changes in gut microbiota. The significant differences in the number of Bifidobacterium, Lactobacillus and Clostridium and in the Firmicutes to Bacteroidetes ratio observed between the two groups could be related to the glycemic level in the group with diabetes. Moreover, the quantity of bacteria essential to maintain gut integrity was significantly lower in the children with diabetes than the healthy children. These findings could be useful for developing strategies to control the development of type 1 diabetes by modifying the gut microbiota.
\end{abstract}

Keywords: butyrate-producing bacteria, glycemic level, gut integrity, gut microbiota, gut permeability, HbA1c level, lactic acid-producing bacteria, mode of delivery, mucin, PCR-DGGE, type 1 diabetes

\footnotetext{
* Correspondence: maribelqo@gmail.com

† Contributed equally

'Biomedical Research Laboratory, Virgen de la Victoria Hospital (FIMABIS),

Campus de Teatinos s/n, Málaga, 29010, Spain

Full list of author information is available at the end of the article
} 


\section{Background}

Type 1 diabetes is a worldwide problem, mainly in children, and it is associated with a significant burden, mostly related to the development of vascular complications [1]. Type 1 diabetes is the result of a complex interaction between different degrees of genetic susceptibility and environmental factors [2-4]. The intestinal microbiota is one of these environmental factors currently under study, partly as a result of observations in both non-obese diabetic (NOD) mice and BioBreeding diabetes-prone rats, where the use of antibiotics was shown to prevent the onset of diabetes [5,6]. Moreover, a recent study using NOD mice suggested that the development of type 1 diabetes can be prevented through modulation of the intestinal microbiota [7]. Newly, Vaarala et al. suggested that the interaction between the intestinal environment, the barrier function and the immune system are crucial in the onset of type 1 diabetes [4]. Using a rat model, Roesch et al. found significant differences at the time of diabetes onset in the bacterial communities responsible for type 1 diabetes modulation [8]. Moreover, other studies have shown that beneficial bacteria, such as probiotic bacteria, have a protective effect in rodent models by delaying or preventing the onset of type 1 diabetes $[9,10]$. With respect to mechanisms of action, Wen et al. found that the gut microbiome of NOD mice lacking an adaptor for multiple innate immune receptors responsible for recognizing microbial stimuli correlates with the disease onset, revealing a relationship between gut microbiota and the immune system [11]. Recent studies have demonstrated that commensal bacteria are crucial for maturation and function of the mucosal immune system. The balance between two major effector $\mathrm{T}$ cell populations in the intestine, IL-17+ T helper 17 cells and Foxp3+ regulatory $\mathrm{T}$ cells, requires signals from commensal bacteria and is dependent on the composition of the intestinal microbiota [12-14]. In addition, increased gut permeability has been observed in patients with type 1 diabetes as well as in NOD mouse and BioBreeding rat models [15-18]. It has been suggested that this increased gut permeability (commonly called leaky gut) may affect the absorption of antigens that can attack and damage pancreatic beta cells [19]. Because gut microbes can affect intestinal permeability, the gut ecology may play a role in the development of type 1 diabetes [20].

Only a few studies have evaluated the ecology of intestinal microbiota in autoimmune children who were not yet diabetic $[21,22]$. These studies used a very low number of participants (four patients and four controls) and neither of them have controlled for such an important factor as the mode of delivery (natural birth or Cesarean) or the type and time of infant feeding (formula-fed or breast-fed), both of which determine the gut microbial composition during infancy $[23,24]$.
The aim of the present study, therefore, was to characterize the composition of fecal microbiota in children with type 1 diabetes as compared with children without diabetes (controlling for such factors as mode of delivery and breastfeeding time) using PCR-denaturing gradient gel electrophoresis (DGGE) and real-time quantitative PCR (qPCR) analysis. This was to determine whether there were significant differences in the gut microbiota composition between these groups and, if so, to quantify the differences and determine the possible relation of the gut microbiota of children with type 1 diabetes with their glycemic level.

\section{Methods}

\section{Study participants and design}

The case-control study included 16 Caucasian children with type 1 diabetes, aged $7.16 \pm 0.72$ years, and 16 healthy Caucasian children, aged $7.48 \pm 0.87$ years. Type 1 diabetes was diagnosed following the criteria of the American Diabetes Association [25,26] and the appearance of at least two persistent, confirmed anti-islet autoantibodies (insulin autoantibodies, glutamic acid decarboxylase autoantibodies or tyrosine phosphatase autoantibodies). The patients with diabetes were treated and monitored according to a standard medical protocol. Patients were excluded if they had any other acute or chronic inflammatory diseases or infectious diseases at study entry. The study participants received no antibiotic treatment, probiotics, prebiotics or any other medical treatment influencing intestinal microbiota during the 3 months before the start of the study. The selected healthy children were all type 1 diabetes autoantibody negative and they were matched to the children with diabetes for age, gender, race, mode of delivery and duration of breastfeeding. The parents of the patients and controls completed a structured interview to obtain the following data: health status, lifestyle aspects (such as living environment and physical activity) and dietary habit. The dietary intake patterns in patients and controls were determined from a food frequency questionnaire that allowed us to assess the consumption of groups of foods. The written guardian or parental consents of the children were obtained. The sampling and experimental processes were performed with the approval of the local Ethics Committee of Ciudad de Jaen hospital. Stool samples were collected by parents at home and delivered to the storage area for frozen storage at $-80^{\circ} \mathrm{C}$ within one hour [27].

\section{Anthropometric measurements}

Body weight and height were measured according to standardized procedures [28]. 


\section{Laboratory measurements}

Fasting venous blood samples were collected. The serum was separated in aliquots and immediately frozen at $-80^{\circ} \mathrm{C}$. Serum biochemical parameters were measured in duplicate. Serum glucose, cholesterol and triglycerides were measured using a standard enzymatic method (Randox Laboratories Ltd., Antrim, UK). The quantitative detection of autoantibodies to islet cell antigens was done using the Elisa RSR GADAb Kit, Elisa RSR IA-2Ab Kit and RIA RSR IAA Kit (RSR Limited, Cardiff, UK).

\section{DNA extraction from fecal samples}

Fecal samples were immediately kept after collection at $-80^{\circ} \mathrm{C}$ and stored until analyzed. DNA extraction from $200 \mathrm{mg}$ of stools was done using the QIAamp DNA Stool Mini Kit (Qiagen, Hilden, Germany) following the manufacturer's instructions. The DNA concentration was determined by absorbance at $260 \mathrm{~nm}$ (A260), and the purity was estimated by determining the A260 to A280 ratio with a Nanodrop spectrophotometer (Nanodrop Technologies, Wilmington, DE, USA).

\section{Analysis of fecal microbiota by PCR-DGGE}

Fecal samples from each participant were examined by determining PCR-DGGE profiles as recently published by us [29]. The V2 to V3 regions of the 16S rRNA genes (positions 339 to 539 in the Escherichia coli gene) of bacteria in the fecal samples were amplified by primers HDA1-GC (5'-CGC CCG CCG CGC GCG GCG GGC GGG GCG GGG GCA CGG GGG GCC TAC GGG AGG CAG CAG T-3'; (the GC clamp is in boldface)) and HDA2 (5'-GTA TTA CCG CGG CTG CTG GCA C-3') generating a $200 \mathrm{bp}$ product. Aliquots $(2 \mu \mathrm{L})$ of DNA were amplified by real-time PCR ( $20 \mu \mathrm{L}$ final volume) in a 7500 Fast Real-Time PCR Systems instrument using Fast SYBR Green Master Mix and $200 \mathrm{nM}$ of each of the universal primers HDA1-GC or HDA2 with the following amplification program: initial denaturation at $95^{\circ} \mathrm{C}$ for 20 $\mathrm{s}$; amplification using 45 cycles including denaturation at $95^{\circ} \mathrm{C}$ for $3 \mathrm{~s}$; annealing at $55^{\circ} \mathrm{C}$ for $30 \mathrm{~s}$; and extension at $72^{\circ} \mathrm{C}$ for $1 \mathrm{~min}$. Negative controls without a DNA template were included in each analysis.

After real-time PCR, $15 \mu \mathrm{L}$ of products were mixed with $6 \mu \mathrm{L}$ of loading dye before loading. Electrophoresis was performed with a DCode Universal Mutation Detection System instrument (Bio-Rad Laboratories, S.A, Madrid, Spain). Six percent polyacrylamide gels were prepared and electrophoresed with $1 \times$ TAE buffer prepared from $50 \times$ TAE buffer (2 M Tris base, $1 \mathrm{M}$ glacial acetic acid, $50 \mathrm{mM}$ ethylenediaminetetraacetic acid (EDTA)). The denaturing gradient was formed by using two $6 \%$ acrylamide (acrylamide to bisacrylamide ratio $37.5: 1$ ) stock solutions (Bio-Rad). The gels contained a $20 \%$ to $80 \%$ gradient of urea and formamide that increases in the direction of electrophoresis. Electrophoretic runs were in a TAE buffer ( $40 \mathrm{mmol} / \mathrm{L}$ Tris, $20 \mathrm{mmol} / \mathrm{L}$ acetic acid, and $1 \mathrm{mmol} / \mathrm{L}$ EDTA, pH 7.4) at $130 \mathrm{~V}$ and $60^{\circ} \mathrm{C}$ for $4.5 \mathrm{~h}$. Electrophoresis was stopped when a xylene cyanol dye marker reached the bottom of a gel. Gels were stained with ethidium bromide $(0.5 \mathrm{mg} / \mathrm{L})$ for $5 \mathrm{~min}$, rinsed with deionized water, viewed by UV transillumination and photographed with Gelcapture image acquisition software (DNR BioImaging Systems Ltd, Mahale HaHamisha, Jerusalen, Israel). All the samples were analyzed on the same DGGE run to avoid the possible influence of variations in electrophoretic conditions between different runs. No band was observed in the negative controls. Similarities between banding patterns in the DGGE profile were calculated based on the presence and absence of bands and expressed as a similarity coefficient. Gels were analyzed using BioNumerics software (Applied Maths, Sint-Martens-Latem, Belgium). Normalized banding patterns were used for cluster analysis. The Dice similarity coefficient was used to calculate pairwise comparisons of the DGGE fingerprint profiles obtained. A similarity coefficient value of $100 \%$ indicates that DGGE profiles are identical while completely different profiles result in a similarity coefficient value of $0 \%$. The unweighted pair group method with arithmetic mean algorithm was used for construction of dendrograms.

\section{Sequencing of selected bands from DGGE gels}

Bands were excised from DGGE gels with a sterile razor, placed in $40 \mu \mathrm{L}$ sterile water and incubated at $4^{\circ} \mathrm{C}$ for diffusion of DNA into the water. DNA were used in a second PCR with HDA1/2 primers without a GC-clamp (initial denaturation at $95^{\circ} \mathrm{C}$ for $20 \mathrm{~s}$, followed by 45 cycles including denaturation at $95^{\circ} \mathrm{C}$ for $3 \mathrm{~s}$, annealing at $55^{\circ} \mathrm{C}$ for $15 \mathrm{~s}$ and extension at $72^{\circ} \mathrm{C}$ for $10 \mathrm{~s}$ ). Subsequently, the PCR products were directly cloned into pCR 4-TOPO (Invitrogen, Carlsbad, CA, USA) according to the manufacturer's instructions. Plasmid DNA was isolated from the cells using the Qiagen Mini Spin Prep Kit (Qiagen), and subjected to PCR (HDA1/2-GC) as earlier described. PCR products were diluted until $20 \mathrm{ng} / \mu \mathrm{L}$, purified with ExoSAP-IT (USB Corporation, Cleveland, OH, USA) and sequenced in an ABI 3130 (Applied Biosystems, Inc., Foster City, CA, USA) using the BigDie-Kit-Standard. Nucleotide sequence data obtained were analyzed using MicroSeqID v2.1.1 software (Applied Biosystems).

\section{Microbial quantification by real-time qPCR}

Specific primers targeting different bacterial genera were used to characterize the fecal microbiota by quantitative real-time qPCR (Table 1) [30-36]. Briefly, quantitative PCR experiments were performed with a LightCycler 2.0 PCR sequence detection system using the FastStart DNA Master SYBR Green kit (Roche Diagnostics, Indianapolis, IN, USA). All PCR tests were carried out in duplicate, 
Table 1 Primers used for real-time PCR

\begin{tabular}{|c|c|c|c|}
\hline Target group & Oligonucleotide sequence $\left(5^{\prime}-3^{\prime}\right)$ & Reference & Amplicon size (bp) \\
\hline \multirow[t]{2}{*}{ Bacteroidetes } & CATGTGGTTTAATTCGATGAT & Guo et al. 2008 [30] & 126 \\
\hline & AGCTGACGACAACCATGCAG & & \\
\hline \multirow[t]{2}{*}{ Bacteroides } & GAGAGGAAGGTCCCCCAC & Guo et al. 2008 [30] & 106 \\
\hline & CGCTACTTGGCTGGTTCAG & & \\
\hline \multirow[t]{2}{*}{ Lactobacillus } & GAGGCAGCAGTAGGGAATCTTC & Delroisse et al. 2008 [31] & 126 \\
\hline & GGCCAGTTACTACCTCTATCCTTCTTC & & \\
\hline \multirow[t]{2}{*}{ Fusobacterium } & CCCTTCAGTGCCGCAGT & Friswell et al. 2010 [32] & 273 \\
\hline & GTCGCAGGATGTCAAGAC & & \\
\hline \multirow[t]{2}{*}{ Firmicutes } & ATGTGGTTTAATTCGAAGCA & Guo et al. 2008 [30] & 126 \\
\hline & AGCTGACGACAACCATGCAC & & \\
\hline \multirow[t]{2}{*}{ Actinobacteria } & CGCGGCCTATCAGCTTGTTG & Stach et al. 2003 [33] & 600 \\
\hline & CCGTACTCCCCAGGCGGGG & & \\
\hline \multirow[t]{2}{*}{ Bifidobacterium } & CTCCTGGAAACGGGTGG & Matsuki et al. 2004 [34] & 550 \\
\hline & GGTGTTCTTCCCGATATCTACA & & \\
\hline \multirow[t]{2}{*}{ Prevotella } & GGTTCTGAGAGGAAGGTCCCC & Bekele et al. 2010 [35] & 121 \\
\hline & TCCTGCACGCTACTTGGCTG & & \\
\hline \multirow[t]{2}{*}{ Enterococcus } & CCCTTATTGTTAGTTGCCATCATT & Rinttilä et al. 2004 [36] & 144 \\
\hline & ACTCGTTCTTCCCATGT & & \\
\hline \multirow[t]{2}{*}{ Proteobacteria } & CATGACGTTACCCGCAGAAGAAG & Friswell et al. 2010 [32] & 195 \\
\hline & CTCTACGAGACTCAAGCTTGC & & \\
\hline \multirow[t]{2}{*}{ Clostridium Cluster IV } & GCACAAGCAGTGGAGT & Matsuki et al. 2004 [34] & 239 \\
\hline & CTTCCTCCGTITTGTCAA & & \\
\hline \multirow[t]{2}{*}{ Blautia coccoides-Eubacterium rectale group } & CGGTACCTGACTAAGAAGC & Rinttilä et al. 2004 [36] & 429 \\
\hline & AGTTTCATTCTTGCGAACG & & \\
\hline \multirow[t]{2}{*}{ Veillonella } & ACCAACCTGCCCTTCAGA & Rinttilä et al. 2004 [36] & 343 \\
\hline & CGTCCCGATTAACAGAGCTT & & \\
\hline \multirow[t]{2}{*}{$\beta$-globin } & GAAGAGCCAAGGACAGGTAC & Fredricks et al. 2007 [37] & 270 \\
\hline & CAACTTCATCCACGTTCACC & & \\
\hline
\end{tabular}

with a final volume of $20 \mu \mathrm{L}$ containing $1 \mu \mathrm{L}$ of each fecal DNA preparation and $200 \mathrm{nM}$ of each primer (Table 1). The thermal cycling conditions used were as follows: an initial DNA denaturation step at $95^{\circ} \mathrm{C}$ for $10 \mathrm{~min} ; 45$ cycles of denaturation at $95^{\circ} \mathrm{C}$ for $10 \mathrm{~s}$; primer annealing at optimal temperature for $20 \mathrm{~s}$; extension at $72^{\circ} \mathrm{C}$ for $15 \mathrm{~s}$. Finally, melt curve analysis was performed by slowly cooling the PCRs from $95^{\circ} \mathrm{C}$ to $60^{\circ} \mathrm{C}\left(0.05^{\circ} \mathrm{C}\right.$ per cycle $)$ with simultaneous measurement of the SYBR Green I signal intensity. Melting-point-determination analysis allowed the confirmation of the specificity of the amplification products. Each participant's extracted DNA was subjected to a human $\beta$-globin PCR to ensure that amplifiable DNA was successfully extracted from the sample and to monitor for PCR inhibitors with the reaction conditions described previously [37]. The bacterial concentration from each sample was calculated by comparing the threshold cycle values obtained from the standard curves with the LightCycler 4.0 software. Standard curves were constructed for each experiment using serial 10-fold dilutions of bacterial genomic DNA (of known concentration) from pure cultures, corresponding to $10^{1}$ to $10^{10}$ copies per gram of feces.
The different strains used were obtained from the Spanish Collection of Type Cultures (CECT) (Bacteroides vulgatus NCTC 11154, Fusobacterium varium NCTC 10560, Enterococcus faecalis CECT 184, Enterobacter cloacae CECT 194, Clostridium perfringens CECT 376) and the American Type Culture Collection (ATCC) (Bifidobacterium bifidum ATCC 15696, Lactobacillus casei ATCC 334D-5, Prevotella intermedia ATCC 25611D-5, Ruminococcus productus ATCC 27340D-5 and Veillonella dispar ATCC 17745). Standard curves were normalized to the copy number of the $16 \mathrm{~S}$ rRNA gene for each species. For species for which the copy number of $16 \mathrm{~S}$ rRNA operon was not published, the copy number was calculated by averaging the operon numbers of the closest bacterial taxa from the ribosomal RNA database rrnDB [38]. Negative controls containing all the elements of the reaction mixture except template DNA were performed in every analysis and no product was ever detected. The data presented are the mean values of duplicate real-time qPCR analyses. The amplification efficiency of the qPCR for all primer pairs was determined using the linear regression slope of a dilution series based on the following equation 
$\mathrm{E}=10^{(-1 / \text { slope })}$. We found that for 13 primer pairs the efficiency ranged from $98 \%(E=1.96)$ to $100 \%(E=2)$ with slopes values in the range of -3.4 to -3.32 .

\section{Statistical analysis}

Results are expressed as mean values and standard deviations. The statistical analysis was performed with SPSS 15.0 software (SPSS Inc., Chicago, IL, USA). The sample size was calculated to obtain a difference in the mean bacterial number between the healthy children and those with type 1 diabetes of at least $2 \times 10^{5}$ copies per gram of feces. With a power of $80 \%$, an alpha error of 0.05 and an estimated standard deviation between group of $1.13 \times 10^{5}$ copies per gram of feces (data obtained from Wu et al. [39]), six children were needed in each group. However, we increased the number of participants to 16 children and 16 controls. The bacterial copy number values were converted into logarithmic values before the statistical analysis. Given the low number of participants analyzed, the Mann-Whitney U test was used to check changes in bacterial number and biochemical variables between the two groups. The Spearman correlation coefficient was calculated to estimate the linear correlations between variables. A multivariate regression analysis was performed to identify individual bacteria as independent predictors for plasma glucose level. Statistical significance was set at a $P$ value of $<0.05$. All data are presented in the text as the mean $\pm \mathrm{SD}$.

\section{Results}

Diet

The healthy children and those with diabetes all had similar physical activity and dietary habits. The analysis of the food frequency questionnaires showed no significant differences in the consumption patterns of rice, wheat, vegetables, fish or meat between the two study groups, although the children with diabetes had a fast carbohydrate restriction (foods made with white flour and refined sugar).

\section{Anthropometric and biochemical measurements}

The anthropometric and biochemical variables of the healthy children and those with diabetes are shown in Table 2. Apart from the levels of glucose and HbA1c, which were significantly higher in the children with diabetes, no other significant differences were seen between the groups in the anthropometric and biochemical variables. In addition, because the healthy children and the children with diabetes were matched for breastfeeding time and mode of delivery, no significant differences were noted in these variables.

\section{PCR-DGGE and bacterial band identification}

Variations were found in the presence or absence (qualitative) and intensity (quantitative) of the bands between the healthy children and the children with diabetes in the host-specific fingerprints generated. DGGE band profiles showed differences in band richness between the two groups. Analysis of the diversity of the microbiota showed that the mean of the DGGE bands was $13.85 \pm 3.87$ for the healthy children and $11.63 \pm 3.64$ for the children with diabetes, though the difference was not significant. Some bands were seen in fingerprints from all the children (in different lanes but at the same position), indicating that specific species of the predominant microbiota were common to all the children.

The Dice similarity coefficient was used to calculate the similarity index between DGGE band profiles related

Table 2 Anthropometric and biochemical variables in healthy children and children with type 1 diabetes

\begin{tabular}{|c|c|c|c|}
\hline & Healthy children & Children with type 1 diabetes & $P$ \\
\hline $\mathbf{N}$ & 16 & 16 & \\
\hline Male/female & $8 / 8$ & $8 / 8$ & \\
\hline Vaginal delivery/Cesarean section & $12 / 4$ & $12 / 4$ & \\
\hline Age of debut (months) & $\mathrm{N} / \mathrm{A}$ & $24.62 \pm 1.52$ & \\
\hline Diabetes duration (years) & $\mathrm{N} / \mathrm{A}$ & $4.84 \pm 1.79$ & \\
\hline Age (years) & $7.48 \pm 0.87$ & $7.16 \pm 0.72$ & 0.266 \\
\hline Body mass index $\left(\mathrm{kg} / \mathrm{m}^{2}\right)$ & $16.35 \pm 0.82$ & $16.57 \pm 0.95$ & 0.489 \\
\hline Weight (kg) & $25.15 \pm 2.12$ & $24.88 \pm 1.98$ & 0.712 \\
\hline Height (cm) & $120.65 \pm 5.05$ & $118.48 \pm 4.96$ & 0.211 \\
\hline Birth weight & $3.33 \pm 0.19$ & $3.42 \pm 0.24$ & 0.249 \\
\hline Glucose (mg/dL) & $84.61 \pm 1.99$ & $158.56 \pm 3.78$ & 0.001 \\
\hline HbA1c (\%) & $4.47 \pm 0.21$ & $7.63 \pm 0.43$ & 0.001 \\
\hline Triglycerides (mg/dL) & $56.54 \pm 6.43$ & $56.93 \pm 4.92$ & 0.849 \\
\hline Cholesterol (mg/dL) & $162.84 \pm 11.46$ & $164.89 \pm 9.76$ & 0.590 \\
\hline Breast feeding time (months) & $3.98 \pm 1.32$ & $4.00 \pm 1.12$ & 0.963 \\
\hline
\end{tabular}

Values are presented as means \pm SD. Relationships between both groups were analyzed using the Mann-Whitney $U$ test. Values are significantly different for $P$ $<0.05$. 
to sampling of healthy children and those with diabetes. The mean similarity index was $47.39 \%$ for the healthy children and $37.56 \%$ for the children with diabetes. The mean similarity index between the groups was $26.69 \%$, lower than the intra-group similarity (Table 3 ). The DGGE gel and the results of the cluster analysis are shown in Figure 1. The cluster analysis showed that the intra-group similarity for the diabetic and the healthy groups was significantly higher than the inter-group similarity. These results demonstrate that the dominant microbiota in the healthy group was different from that of the diabetic group.

All the bands from the profiles of all the healthy children and the children with diabetes were cloned and sequenced to identify the dominant microbiota. The sequence similarity matches for bands were analyzed by MicroSeqID v2.1.1 software. Bacterial identification showed that the majority of bacteria represented in the fingerprints obtained corresponded to five phyla (Table 4). Most of the sequences belonged to Firmicutes and Bacteroidetes, with the rest distributed among Actinobacteria, Fusobacteria and Proteobacteria. Nevertheless, we observed important differences between the healthy children and the children with diabetes in the distribution ratio of the different genera within Bacteroidetes, Firmicutes and Actinobacteria phyla. In the children with diabetes, we found an increase in the Clostridium, Bacteroides, Veillonella, Eggerthella and Bacillus frequencies and a disappearance of Prevotella and Bifidobacterium as compared with the healthy children (Table 4).

\section{Comparative analysis of gut microbiota communities in healthy children and children with diabetes}

Changes in the bacterial population abundance were assessed in the fecal samples of both groups. The results obtained in the real-time qPCR experiments with the different primers are shown in Tables 5 and 6. Relevant differences were found in the bacteria number of three phyla between the diabetic and the healthy children. The

Table 3 Microbiota diversity and similarity of healthy and type 1 diabetes groups of children

\begin{tabular}{lccc}
\hline & Microbiota diversity & \multicolumn{2}{c}{ Microbiota similarity } \\
\cline { 2 - 4 } & $\begin{array}{c}\text { DGGE bands } \\
\text { (means } \pm \text { SD) }\end{array}$ & Intra-group $^{\mathbf{b}}$ & Inter-group $^{\mathbf{c}}$ \\
\hline Healthy & $13.85 \pm 3.87$ & $47.39 \pm 4.35$ & $26.69 \pm 6.78$ \\
Diabetic & $11.63 \pm 3.64$ & $37.56 \pm 5.67$ & \\
$\boldsymbol{P}$ & 0.105 & 0.001 & 0.000 \\
\hline
\end{tabular}

Values are presented as means \pm SD. Data were analyzed using the MannWhitney $U$ test. Values are significantly different for $P<0.05$. ${ }^{\text {a Number of }}$ DGGE bands produced by each sample analyzed. ${ }^{b}$ Dice similarity coefficients comparing DGGE band profiles within individuals of the same group. 'Dice similarity coefficients comparing DGGE band profiles between members of the type 1 diabetes and the healthy groups. number of Actinobacteria, Firmicutes and Bacteroidetes were significantly different between groups whilst the quantity of Proteobacteria and Fusobacteria were similar between the groups. In the children with diabetes, the bacterial number of Actinobacteria and Firmicutes was significantly decreased while that of Bacteroidetes was significantly increased with respect to the healthy children. Moreover, the Firmicutes to Bacteroidetes ratio was significantly lower in the children with diabetes than the healthy children.

Within Firmicutes, the quantity of Veillonella was significantly higher and the number of bacteria from the Blautia coccoides-Eubacterium rectale group was significantly lower in the children with diabetes compared with the healthy children. The Lactobacillus number was significantly lower and Clostridium levels significantly higher in the children with diabetes. However, no significant differences were found in Enterococcus levels between the two groups. Within Bacteroidetes, the quantity of Bacteroides was significantly higher whereas the number of Prevotella was significantly lower in the children with diabetes compared with the healthy children. Finally, within Actinobacteria, the number of Bifidobacterium was significantly lower in the children with diabetes.

\section{Relationship between gut microbiota composition in children with type 1 diabetes and glycemic level}

In the children with diabetes, we found a significant univariate correlation between the amount of specific bacterial groups and the plasma glucose levels (Bifidobacterium $\mathrm{r}=-0.797, P=0.008$; Clostridium $\mathrm{r}=0.676, P<0.05$; Lactobacillus $\mathrm{r}=-0.698, P<0.05$; and Firmicutes to Bacteroidetes ratio $\mathrm{r}=-0.473, P<0.05$ ) and HbA1c levels (Bifidobacterium $\mathrm{r}=-0.573, \mathrm{P}<0.05 ;$ Clostridium $\mathrm{r}=0.452$, $P<0.05$; Firmicutes $\mathrm{r}=-0.559, P<0.05$; Firmicutes to Bacteroidetes ratio $r=-0.765, P=0.012$ ). A multivariate regression analysis that included all the bacterial groups analyzed showed that only the reduction in the number of Bifidobacterium and Lactobacillus was associated with the plasma glucose level $\left(P<0.05, \beta=-0.476, R^{2}=0.587\right.$; and $P$ $=0.012, \beta=-0.687, R^{2}=0.539$, respectively) whereas the higher HbA1c level was associated with the decrease in the Firmicutes to Bacteroidetes ratio $\left(P<0.001, \beta=-1.047, \mathrm{R}^{2}=\right.$ $0.781)$ and the increase in the number of Clostridium $(P=$ $0.016, \beta=0.867, R^{2}=0.499$ ).

\section{Discussion}

In the present study we found significant differences in the fecal microbial composition between healthy children and children with type 1 diabetes. We are unaware of any other similar studies in children with type 1 diabetes using simultaneously DGGE molecular profiling, unweighted pair group method with arithmetic mean algorithm 


\section{A $\quad$ B $\quad$ C}

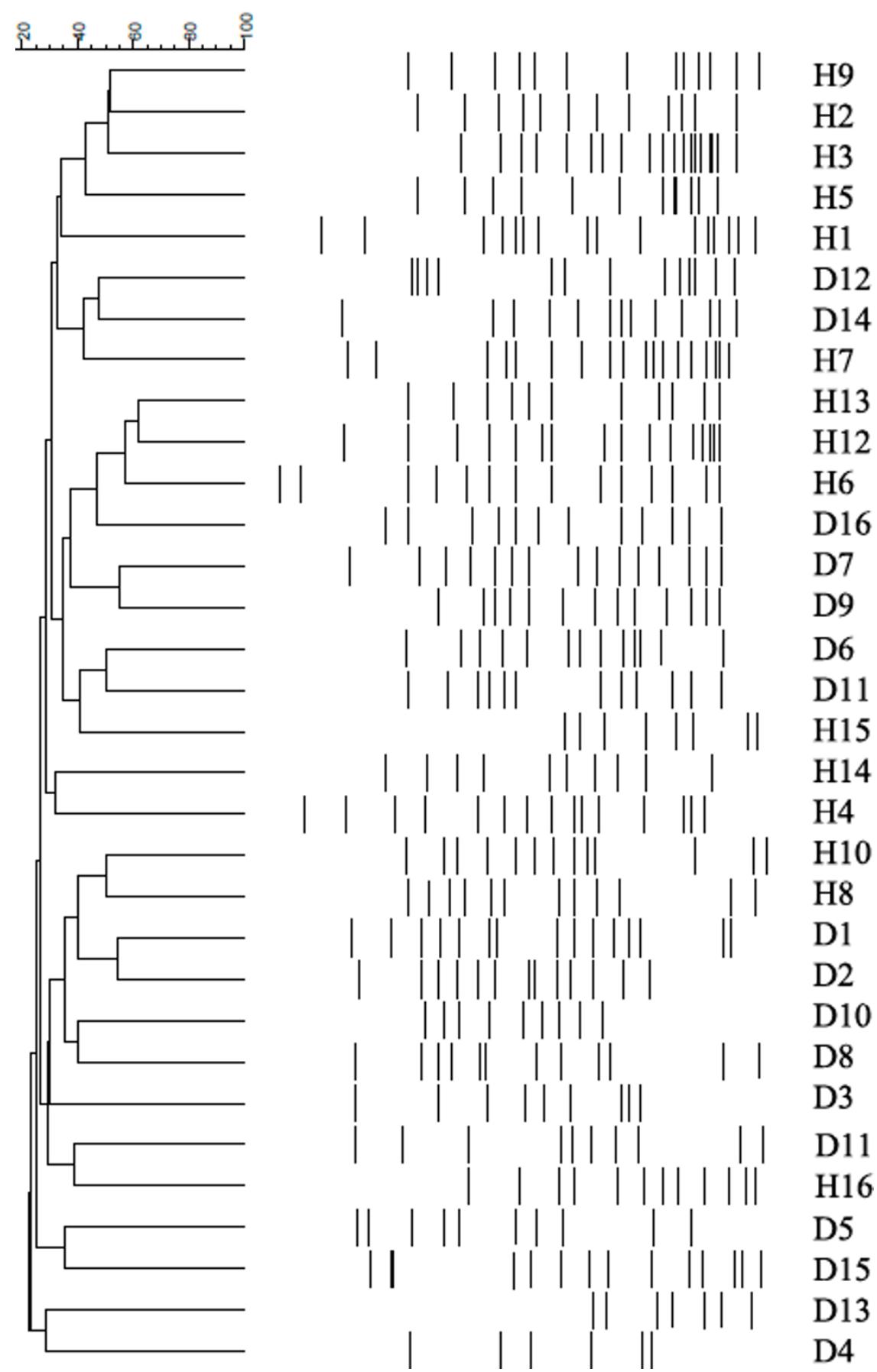

Figure 1 Cluster analysis. Dendrograms of electrophoretic band patterns obtained in the denaturing gel gradient electrophoresis experiment with universal primers in the fecal samples collected from healthy children (H) and those with type 1 diabetes (D). (A) Cluster analysis; (B) DGGE profiles related to fecal samples; (C) line graph.

dendrogram construction, sequencing and real-time qPCR analysis. To determine the characteristics of the gut microbiota based on the condition of just type 1 diabetes, we excluded the influence of physiological factors such as age, gender, dietary habits and race. In addition, we also controlled for the mode of delivery at birth and the duration of breastfeeding. This was because the first year of life has a crucial impact on gut microbiota composition and 
Table 4 Bacterial identification after sequencing the bands cloned from the DGGE analysis of fecal samples in the healthy and diabetic groups

\begin{tabular}{|c|c|c|c|}
\hline Identification & $\begin{array}{l}\text { Healthy group }{ }^{a} \\
(n=52)\end{array}$ & $\begin{array}{l}\text { Diabetes group }{ }^{a} \\
(n=50)\end{array}$ & Sequence similarity (\%) \\
\hline \multicolumn{4}{|c|}{ Phylum Firmicutes } \\
\hline Veillonella & $4(7.7 \%)$ & $9(18 \%)$ & 99.97 \\
\hline Bacillus & 0 & $2(4 \%))$ & 99.82 \\
\hline Clostridium & $6(11.5 \%)$ & $15(30 \%)$ & 99.95 \\
\hline Gemella & $4(10 \%)$ & $2(4 \%)$ & 99.86 \\
\hline \multicolumn{4}{|c|}{ Phylum Fusobacteria } \\
\hline Leptotrichia & $4(7.7 \%)$ & $3(6 \%)$ & 99.94 \\
\hline \multicolumn{4}{|c|}{ Phylum Actinobacteria } \\
\hline Bifidobacterium & $6(11.5 \%)$ & 0 & 99.75 \\
\hline Eggerthella & 0 & $4(8 \%)$ & 99.90 \\
\hline \multicolumn{4}{|c|}{ Phylum Proteobacteria } \\
\hline Desulfovibrio & $4(7.7 \%)$ & $3(6 \%)$ & 99.75 \\
\hline \multicolumn{4}{|c|}{ Phylum Bacteroidetes } \\
\hline Prevotella & $16(30.7 \%)$ & 0 & 99.68 \\
\hline Bacteroides & $5(9.6 \%)$ & $10(20 \%)$ & 99.89 \\
\hline Pedobacter & $3(5.8 \%)$ & $2(4 \%)$ & 99.47 \\
\hline
\end{tabular}

${ }^{a}$ Refers to the frequency (and percent) of each unique bacteria genus in the type 1 diabetic group and healthy group. $\mathrm{n}$ refers to the number of bands cloned, sequenced and identified in each study group. $\mathrm{N}=16$ participants per group.

epidemiological studies in humans at genetic risk for type 1 diabetes have suggested that a short duration of breastfeeding and early feeding in infancy with complex dietary proteins such as cow's milk proteins can modulate the development of beta cell autoimmunity, clinical type 1 diabetes, or both [40-42]. No significant differences were found between the two groups of children (type 1 diabetes and controls).

The DGGE analysis of the fecal microbiota revealed a significantly lower intra-group similarity index in children with diabetes than in healthy children. In other words, the DGGE profiles in healthy children were more similar to each other, whereas in children with diabetes they were less similar. A similar result was found by Giongo et al. [21]. These data suggest that diabetic status may influence specific bacterial groups of the gut microbiota community.
Sequence analysis of the DGGE bands cloned enable the association of specific bacterial genotypes with health or diabetes situations. Consistent with previous human and animal studies $[11,21,39,37,43]$, the gut microbiota of healthy children and children with diabetes was predominately composed of Firmicutes and Bacteroidetes and the main difference lies in the proportion of genus-division bacteria within this two phyla and the Actinobacteria phylum between both the group with diabetes and the healthy group. These results suggest that the dominant microbiota genera are different in children with type 1 diabetes compared with healthy children. Recently, three robust clusters, referred to as "enterotypes", which are not nation or continent specific have been identified. Assignment of an individual microbiome into a given enterotype is based upon the relative enrichment of that microbiome in one of three genera:

Table 5 Real-time PCR quantification of microbiota phyla in healthy children and children with type 1 diabetes

\begin{tabular}{lccc}
\hline & Healthy children & Children with type 1 diabetes & $P$ \\
\hline Proteobacteria & $7.74 \pm 0.64$ & $7.97 \pm 1.12$ & 0.481 \\
Actinobacteria & $6.32 \pm 0.45$ & $5.47 \pm 0.93$ & 0.003 \\
Fusobacteria & $6.61 \pm 1.19$ & $6.99 \pm 1.28$ & 0.391 \\
Firmicutes & $9.85 \pm 0.43$ & $6.54 \pm 0.56$ & 0.001 \\
Bacteroidetes & $9.98 \pm 0.74$ & $10.92 \pm 0.83$ & 0.002 \\
Firmicutes to Bacteroidetes ratio & $0.97 \pm 0.19$ & $0.62 \pm 0.24$ & 0.001 \\
\hline
\end{tabular}

Values are presented as means $\pm S D$ and expressed as $\log _{10}$ copies per gram of feces. $N=16$ participants per group. Relationships between both groups were analyzed using the Mann-Whitney $U$ test. Values are significantly different for $P<0.05$. 
Table 6 Genera and groups within the phyla Firmicutes, Bacteroidetes and Actinobacteria in healthy children and children with type 1 diabetes

\begin{tabular}{lccc}
\hline & $\begin{array}{c}\text { Healthy } \\
\text { children } \\
10.95 \pm 0.57\end{array}$ & $\begin{array}{c}\text { Children with type } \mathbf{1} \\
\text { diabetes }\end{array}$ & $\boldsymbol{P}$ \\
Prevotella & $4.85 \pm 0.34$ & $9.03 \pm 0.99$ & 0.001 \\
Clostridium & $8.64 \pm 0.72$ & $6.99 \pm 0.52$ & 0.001 \\
$\begin{array}{l}\text { B. Coccoides-E } \\
\text { rectale }\end{array}$ & $5.80 \pm 1.35$ & $5.94 \pm 1.21$ & 0.001 \\
Enterococcus & $6.76 \pm 0.82$ & $8.93 \pm 1.12$ & 0.760 \\
Veillonella & $5.65 \pm 1.14$ & $3.12 \pm 0.97$ & 0.001 \\
Bifidobacterium & $4.23 \pm 0.36$ & $3.47 \pm 0.43$ & 0.001 \\
Lactobacillus & $8.64 \pm 0.45$ & $10.67 \pm 0.63$ & 0.001 \\
Bacteroides & C. & 0.001 \\
\hline
\end{tabular}

Values are presented as means \pm SD and expressed as $\log _{10}$ copies per gram of feces. $\mathrm{N}=16$ participants per group. Relationships between both groups were analyzed using the Mann-Whitney $U$ test. Values are significantly different for $P<0.05$

Bacteroides (enterotype 1), Prevotella (enterotype 2) or Ruminococcus (enterotype 3) [44]. In this study, within Bacteroidetes, the Bacteroides genus was prevalent in the diabetic group, whereas the Prevotella genus was associated with the healthy group. Thus, the type 1 diabetic gut microbiomes could be classified into enterotype 1 and the healthy microbiomes could be classified into enterotype 2.

As DGGE is considered a semiquantitative tool for monitoring the dynamics of the predominant bacterial species of fecal microbiota, an additional analysis with real-time qPCR was performed to obtain a quantitative estimation of the changes found in the gut microbiota between children with diabetes and healthy children. We noted significant quantitative differences between the major microbial phyla present in the feces of healthy children and those with diabetes. In contrast to the situation in healthy children, we found a significant increase in the quantity of Bacteroidetes and a significant decrease in the number of Firmicutes and Actinobacteria in children with type 1 diabetes. Our data showed a significantly lower Firmicutes to Bacteroidetes ratio in children with type 1 diabetes compared with healthy children. Moreover, we saw a negative correlation between this ratio and both the glucose and the HbA1C levels in children with diabetes, which could help to explain the significantly higher glycemic level in this group. In agreement with this, Giongo et al. observed that the Firmicutes to Bacteroidetes ratio in study participants with type 1 diabetes was changing during the first 6 months after birth before the development of the autoimmune disease. These authors showed a successive decline in Firmicutes and an increase in Bacteroidetes number in the gut microbiome over time until the children became diabetic [21]. Moreover, this imbalance observed at the phylum level between Bacteroidetes and Firmicutes has been previously described in several human disorders. A decline in the Firmicutes to Bacteroidetes ratio compared with controls has been described in human type 2 diabetes [45], whereas in Crohn's disease, both Bacteroidetes and Firmicutes seem to decline [46]. The opposite happens in obesity, where the imbalance is due to the increase in the Firmicutes to Bacteroidetes ratio [47], indicating that obesity and diabetes are associated with different groups of intestinal microbiota.

However, the major difference between the two groups was found in the number of bacteria at genus-division level. The most remarkable result was the significant increase in the number of Clostridium, Bacteroides and Veillonella in the children with diabetes, whereas the number of Lactobacillus, Bifidobacterium, the Blautia coccoides/Eubacterium rectale group and Prevotella genus were all significantly decreased in children with diabetes. Our findings concerning the microbiota of children with diabetes are in line with observations in other animal studies. Roesch et al. found higher levels of Lactobacillus and Bifidobacterium in BioBreeding diabetes-resistant rats whereas Bacteroides and Clostridium were more abundant in BioBreeding diabetes-prone rats [27]. In contrast with this, however, Brown et al. found that Lactobacillus and Bifidobacterium were more abundant in participants with type 1 diabetes than in healthy participants [22].

The significant decrease in the number of Lactobacillus and Bifidobacterium observed in children with type 1 diabetes in our study was associated with their higher levels of plasma glucose, as indicated by the negative correlation found. Also, the regression analysis showed that the decrease in the number of Lactobacillus and Bifidobacterium could be associated with the plasma glucose level in the children with diabetes. In previous studies, the levels of Bifidobacterium have also been related to improved glucose metabolism, insulin resistance and low-grade inflammation $[48,49]$. Moreover, Valladares et al. determined that the administration of Lactobacillus johnsonii isolated from BioBreeding diabetes-resistant rats delays or inhibits the onset of type 1 diabetes in BioBreeding diabetes-prone rats [10].

Both Lactobacillus and Bifidobacterium have members with probiotic characteristics and these have been associated with positive effects for the host in the large intestine [50]. In addition, both bacterial groups have the capacity to produce the beneficial organic acid lactate, which is converted into butyrate by butyrate-producing bacteria in the gut [22]. Barcenilla et al. [51] showed that most of the butyrate-producing isolates from human fecal samples are related to the Blautia coccoides-Eubacterium rectale group. Previous studies have shown that butyrate induces mucin synthesis (a glycoprotein produced by the host that could maintain the integrity of the gut epithelium) [52], decreases bacterial transport across the 
epithelium [53], and improves gut integrity by increasing tight junction assembly [54]. In addition, the genera Prevotella are responsible for the degradation of this mucin [55]; thus, the significant decline in the numbers of the Blautia coccoides-Eubacterium rectale group and Prevotella that we found in children with type 1 diabetes compared with healthy children could indicate a reduction in mucin synthesis by the host and a lack of this mucin on the epithelial layer of the gut, which would lead to a significant alteration in intestinal permeability. Other studies have described an association between type 1 diabetes and compromised barrier permeability in humans and both the NOD mouse and BioBreeding rat models [16-18,20].

The significant increase in the number of Clostridium, Bacteroides and Veillonella in the children with diabetes with respect to the healthy children was accompanied by a significant positive correlation between both the plasma levels of glucose and HbA1c and the quantity of Clostridium. These bacteria are able to ferment glucose and lactate to propionate, acetate and succinate. However, these short fatty acids do not induce mucin synthesis [52]. This situation would, though, reduce the tight junction assembly, generating an increase in the gut permeability in children with type 1 diabetes [22].

Finally, we propose a possible mechanism to explain the relationship we have found between the gut microbiota present in children with type 1 diabetes and the glycemic levels observed. The short-chain fatty acids (such as butyrate and propionate) formed by this gut microbiota have a role in the regulation of the levels of gut hormones such as glucose-dependent insulinotropic polypeptide, glucagon-like peptide 1 and ghrelin. These hormones have important effects on carbohydrate metabolism [56], thus allowing gut microbiota to affect glycemic levels. In addition, Huml et al. have previously demonstrated an altered secretion pattern of gut hormones in children with type 1 diabetes that may impact on the metabolic control of diabetes in these patients [57]. Further studies will be necessary to demonstrate this proposed mechanism.

A limitation of the $16 \mathrm{~S}$ rRNA gene-based method is that the function of the identified bacteria is unknown. Future studies using a microbial metagenomic sequencing analysis will be carried out to obtain information about the functional diversity of the bacterial community analyzed here.

\section{Conclusions}

This is the first study showing that type 1 diabetes is associated with compositional changes in gut microbiota. Our results show that gut microbiota found in children with type 1 diabetes differed significantly from that found in healthy children. The gut microbiota in the children with diabetes was less similar than the gut microbiota in the healthy children. The significant differences between the diabetic and the healthy children in the number of Bifidobacterium, Lactobacillus and Clostridium and the Firmicutes to Bacteroidetes ratio could be implicated in the glycemic level of the children with diabetes. In addition, the numbers of lactic acid-producing bacteria, butyrate-producing bacteria and mucin-degrading bacteria, essential to maintain gut integrity, were significantly lower in the children with diabetes than the healthy children. These bacterial differences could be responsible for the altered gut permeability previously described in patients with type 1 diabetes. These findings could be useful for developing strategies to control the development of type 1 diabetes by modifying the gut microbiota.

\section{Abbreviations}

bp: base pairs; DGGE: denaturing gradient gel electrophoresis; EDTA: ethylenediaminetetraacetic acid; NOD: non-obese diabetic mice; PCR: polymerase chain reaction; QPCR: quantitative polymerase chain reaction; SD: standard deviation; TAE: buffer with Tris base, glacial acetic acid and ethylenediaminetetraacetic acid.

\section{Authors' contributions}

IL, FC, FS, FJT and MIQO conceived the study and developed the experimental design. IL, FS, FJT and MIQO were responsible for acquisition and selection of all samples utilized in this study. MM, IL, FC, JMGZ and MIQO performed all laboratory assays. MM, IL, JMGZ, FC and MIQO compiled the database and performed statistical analysis and data interpretation. MM, IL, JMGZ, FC, FS, FJT and MIQO wrote the paper. FS, FJT and MIQO provided critical revision. All the authors have read and approved the final manuscript.

\section{Competing interests}

The authors declare that they have no competing interests.

\section{Acknowledgements}

The authors wish to thank all the participants for their collaboration and the Plataforma de Secuenciacion y Genotipado and the Unidad Central de Biología Molecular (Servicio de PCR a tiempo real) of FIMABIS for their help in laboratory assays. We also gratefully acknowledge the help of lan Johnstone for his expertise in preparing this manuscript. The research group belongs to the Centros de Investigación en Red (CIBEROBN, CB06/03/0018 and CIBERDEM, CB07/08/0019) of the Instituto de Salud Carlos III. This work was partially funded by a grant from CIBER, CB06/03/0018 of the Instituto de Salud Carlos III to MM, FC, FJT and MIQO; the Instituto de Salud Carlos III, Madrid, Spain (CP07/0095) to FJT; and the Servicio Andaluz de Salud, Andalucía, Spain (PI0696/2010) to FJT. The funding agencies had no role in the design and performance of the study, the interpretation of the data or the writing of the manuscript.

\section{Author details}

'Biomedical Research Laboratory, Virgen de la Victoria Hospital (FIMABIS), Campus de Teatinos s/n, Málaga, 29010, Spain. ²Pediatric Endocrinology Service, Carlos Haya Materno Infantil Hospital, Avenida Arroyo de los Angeles, Málaga, 29011, Spain. ${ }^{3}$ Molecular Biology Laboratory, Civil Hospital (IMABIS foundation), Plaza Hospital Civil s/n, Málaga, 29009, Spain. ${ }^{4}$ CIBER of Physiopathology of Obesity and Nutrition (CIBEROBN), Instituto de Salud Carlos III, C/ Sinesio Delgado no 4, Madrid, 28029, Spain. ${ }^{5}$ Endocrinology and Nutrition Service, Carlos Haya Hospital, Plaza Hospital Civil s/n, Málaga, 29009, Spain. ${ }^{6} \mathrm{CIBER}$ of Diabetes and Metabolic Diseases (CIBERDEM), Instituto de Salud Carlos III, C/ Sinesio Delgado n 4, Madrid, 28029, Spain. ${ }^{7}$ Endocrinology and Nutrition Service, Virgen de la Victoria Hospital, Campus de Teatinos s/n, Málaga, 29010, Spain. 
Received: 15 August 2012 Accepted: 21 February 2013

Published: 21 February 2013

\section{References}

1. Marcovecchio ML, Tossavainen PH, Dunger DB: Prevention and treatment of microvascular disease in childhood type 1 diabetes. Br Med Bull 2010, 94:145-164.

2. Ehehalt S, Dietz K, Willasch AM, Neu A, Baden-Württemberg : Diabetes Incidence Registry (DIARY) Group. Epidemiological perspectives on type 1 diabetes in childhood and adolescence in Germany: 20 years of the Baden-Württemberg Diabetes Incidence Registry (DIARY). Diabetes Care 2010, 3:338-340.

3. Patterson CC, Dahlquist G, Soltesz G, Green A, Grp EAS: Is childhood onset Type I diabetes a wealth-related disease? An ecological analysis of European incidence rates. Diabetologia 2001, 4:9-16.

4. Vaarala O, Atkinson MA, Neu J: The "perfect storm" for type 1 diabetes the complex interplay between intestinal microbiota, gut permeability, and mucosal immunity. Diabetes 2008, 57:2555-2562.

5. Brugman S, Klatter FA, Visser JT, Wildeboer-Veloo AC, Harmsen HJ, Rozing J, Bos NA: Antibiotic treatment partially protects against type 1 diabetes in the Bio-Breeding diabetes-prone rat. Is the gut flora involved in the development of type 1 diabetes? Diabetologia 2006, 49:2105-2108.

6. Schwartz RF, Neu J, Schatz D, Atkinson MA, Wasserfall C: Comment on: Brugman S et al. (2006) Antibiotic treatment partially protects against type 1 diabetes in the Bio-Breeding diabetes-prone rat. Is the gut flora involved in the development of type 1 diabetes? Diabetologia 49:21052108. Diabetologia 2007, 50:220-221.

7. King C, Sarvetnick N: The incidence of type-1 diabetes in NOD mice is modulated by restricted flora not germ-free conditions. Plos One 2011, 6: e17049.

8. Roesch LFW, Lorca GL, Casella G, Giongo A, Naranjo A, Pionzio AM, Li N, Mai V, Wasserfall CH, Schatz D, Atkinson MA, Neu J, Triplett EW: Cultureindependent identification of gut bacteria correlated with the onset of diabetes in a rat model. Isme J 2009, 3:536-548.

9. Lai KK, Lorca GL, Gonzalez CF: Biochemical properties of two cinnamoyl esterases purified from a Lactobacillus johnsonii strain isolated from stool samples of diabetes-resistant rats. Appl Environ Microbiol 2009, 75:5018-5024

10. Valladares R, Sankar D, Li N, Williams E, Lai KK, Abdelgeliel AS, Gonzalez CF, Wasserfall CH, Larkin J, Schatz D, Atkinson MA, Triplett EW, Neu J, Lorca GL: Lactobacillus johnsonii N6.2 mitigates the development of type 1 diabetes in BB-DP rats. PLOS One 2010, 5:e10507.

11. Wen L, Ley RE, Volchkov PY, Stranges PB, Avanesyan L, Stonebraker AC, Hu C, Wong FS, Szot GL, Bluestone JA, Gordon Jl, Chervonsky AV: Innate immunity and intestinal microbiota in the development of Type 1 diabetes. Nature 2008, 45:1109-1113.

12. Ivanov II, Atarashi K, Manel N, Brodie EL, Shima T, Karaoz U, Wei D, Goldfarb KC, Santee CA, Lynch SV, Tanoue T, Imaoka A, Itoh K, Takeda K Umesaki Y, Honda K, Littman DR: Induction of intestinal Th17 cells by segmented filamentous bacteria. Cell 2009, 139:485-498.

13. Ivanov II, Littman DR: Segmented filamentous bacteria take the stage. Mucosal Immunol 2010, 3:209-212.

14. Romano-Keeler J, Weitkamp JH, Moore DJ: Regulatory properties of the intestinal microbiome effecting the development and treatment of diabetes. Curr Opin Endocrinol Diabetes Obes 2012, 19:73-80.

15. Kuitunen M, Saukkonen T, llonen J, Akerblom HK, Savilahti E: Intestinal permeability to mannitol and lactulose in children with type 1 diabetes with the HLA-DQB1*02 allele. Autoimmunity 2002, 35:365-368.

16. Watts T, Berti I, Sapone A, Gerarduzzi T, Not T, Zielke R, Fasano A: Role of the intestinal tight junction modulator zonulin in the pathogenesis of type I diabetes in BB diabetic-prone rats. Proc Natl Acad Sci 2005, 102:2916-2921.

17. Bosi E, Molteni L, Radaelli MG, Folini L, Fermo I, Bazzigaluppi E, Piemonti L, Pastore MR, Paroni R: Increased intestinal permeability precedes clinical onset of type 1 diabetes. Diabetologia 2006, 49:2824-2827.

18. Lee AS, Gibson DL, Zhang Y, Sham HP, Vallance BA, Dutz JP: Gut barrier disruption by an enteric bacterial pathogen accelerates insulitis in NOD mice. Diabetologia 2010, 53:741-748

19. Vehik K, Dabelea D: The changing epidemiology of type 1 diabetes: why is it going through the roof? Diabetes Metab Res Rev 2011, 27:3-13.
20. Mathis $D$, Benoist $C$ : The influence of the microbiota on type- 1 diabetes: on the threshold of a leap forward in our understanding. Immunol Rev 2012, 245:239-249

21. Giongo A, Gano KA, Crabb DB, Mukherjee N, Novelo LL, Casella G, Drew JC, Ilonen J, Knip M, Hyöty H, Veijola R, Simell T, Simell O, Neu J, Wasserfall CH, Schatz D, Atkinson MA, Triplett EW: Toward defining the autoimmune microbiome for type 1 diabetes. Isme J 2011, 5:82-91.

22. Brown CT, Davis-Richardson AG, Giongo A, Gano KA, Crabb DB, Mukherjee N, Casella G, Drew JC, llonen J, Knip M, Hyöty H, Veijola R, Simell T, Simell O, Neu J, Wasserfall CH, Schatz D, Atkinson MA, Triplett EW: Gut microbiome metagenomics analysis suggests a functional model for the development of autoimmunity for type 1 diabetes. PLoS One 2011, 6:e25792.

23. Penders J, Thijs C, Vink C, Stelma FF, Snijders B, Kummeling I, van den Brandt PA, Stobberingh EE: Factors influencing the composition of the intestinal microbiota in early infancy. Pediatrics 2006, 118:511-521.

24. Musso G, Gambino R, Cassader M: Obesity, diabetes, and gut microbiota: the hygiene hypothesis expanded? Diabetes Care 2010, 3:2277-2284.

25. Report of the Expert Committee on the diagnosis and classification of diabetes mellitus. Diabetes Care 1997, 20:1183-1197.

26. American Diabetes Association: Diagnosis and classification of diabetes mellitus. Diabetes Care 2010, 3:S62.

27. Roesch LF, Casella G, Simell O, Krischer J, Wasserfall CH, Schatz D, Atkinson MA, Neu J, Triplett EW: Influence of sample storage on bacterial community diversity in fecal samples. Open Microbiol J 2009, 3:40-46.

28. Standardization of anthropometric measurements. In The Airlie (VA) Consensus Conference. Edited by: Loham T, Roche A, Martorel R. Champaign, IL: Human Kinetics; 1988:20-37.

29. Queipo-Ortuño MI, Boto-Ordóñez M, Murri M, Gomez-Zumaquero JM, Clemente-Postigo M, Estruch R, Cardona Diaz F, Andrés-Lacueva C, Tinahones FJ: Influence of red wine polyphenols and ethanol on the gut microbiota ecology and biochemical biomarkers. Am J Clin Nutr 2012, 95:1323-1334.

30. Guo X, Xia X, Tang R, Zhou J, Zhao H, Wang K: Development of a realtime PCR method for Firmicutes and Bacteroidetes in faeces and its application to quantify intestinal population of obese and lean pigs. Lett Appl Microbiol 2008, 47:367-373.

31. Delroisse JM, Boulvin AL, Parmentier I, Dauphin RD, Vandenbol M, Portetelle D: Quantification of Bifidobacterium spp. and Lactobacillus spp. in rat fecal samples by real-time PCR. Microbiol Res 2008, 163:663-670.

32. Friswell MK, Gika H, Stratford IJ, Theodoridis G, Telfer B, Wilson ID, McBain AJ: Site and strain-specific variation in gut microbiota profiles and metabolism in experimental mice. PLoS One 2010, 5:e8584.

33. Stach JE, Maldonado LA, Ward AC, Goodfellow M, Bull AT: New primers for the class Actinobacteria: application to marine and terrestrial environments. Environ Microbiol 2003, 5:828-841.

34. Matsuki T, Watanabe K, Fujimoto J, Takada T, Tanaka R: Use of 16S rRNA genetargeted group-specific primers for real-time PCR analysis of predominant bacteria in human feces. Appl Environ Microbiol 2004, 70:7220-7228.

35. Bekele AZ, Koike S, Kobayashi Y: Genetic diversity and diet specificity of ruminal Prevotella revealed by $16 \mathrm{~S}$ rRNA gene-based analysis. FEMS Microbiol Lett 2010, 305:49-57.

36. Rinttilä $T$, Kassinen A, Malinen E, Krogius L, Palva A: Development of an extensive set of $16 \mathrm{~S}$ rDNA-targeted primers for quantification of pathogenic and indigenous bacteria in faecal samples by real-time PCR. J Appl Microbiol 2004, 97:1166-1177.

37. Fredricks DN, Fiedler TL, Thomas KK, Oakley BB, Marrazzo JM: Targeted PCR for detection of vaginal bacteria associated with bacterial vaginosis. $J$ Clin Microbiol 2007, 45:3270-3276.

38. Lee ZMP, Bussema C, Schmidt TM: rrnDB: documenting the number of rRNA and tRNA genes in bacteria and archaea. Nucleic Acids Res 2009, 37:489-493.

39. Wu X, Ma C, Han L, Nawaz M, Gao F, Zhang X, Yu P, Zhao C, Li L, Zhou A, Wang J, Moore JE, Millar BC, Xu J: Molecular characterisation of the faecal microbiota in patients with type II diabetes. Curr Microbiol 2010, 61:69-78.

40. Stuebe A: The risks of not breastfeeding for mothers and infants. Rev Obstet Gynecol 2009, 2:222-231.

41. Vaarala $\mathrm{O}$ : The gut as a regulator of early inflammation in type 1 diabetes. Curr Opin Endocrinol Diabetes Obes 2011, 18:241-247.

42. Knip M, Virtanen SM, Becker D, Dupré J, Krischer JP, Åkerblom HK, TRIGR Study Group: Early feeding and risk of type 1 diabetes: experiences from 
the Trial to Reduce Insulin-dependent diabetes mellitus in the Genetically at Risk (TRIGR). Am J Clin Nutr 2011, 94:1814-1820.

43. Gill SR, Pop M, Deboy RT, Eckburg PB, Turnbaugh PJ, Samuel BS, Gordon Jl, Relman DA, Fraser-Liggett CM, Nelson KE: Metagenomic analysis of the human distal gut microbiome. Science 2006, 312:1355-1359.

44. Arumugam M, Raes J, Pelletier E, Le Paslier D, Yamada T, Mende DR, Fernandes GR, Tap J, Bruls T, Batto JM, Bertalan M, Borruel N, Casellas F, Fernandez L, Gautier L, Hansen T, Hattori M, Hayashi T, Kleerebezem M, Kurokawa K, Leclerc M, Levenez F, Manichanh C, Nielsen HB, Nielsen T, Pons N, Poulain J, Qin J, Sicheritz-Ponten T, Tims S, et al: Enterotypes of the human gut microbiome. Nature 2011, 473:174-180.

45. Larsen N, Vogensen FK, van den Beg FWL, Nielsen DS, Andreasen AS, Pedersen BK, Al-Soud WA, Sørensen SJ, Hansen LH, Jakobsen M: Gut microbiota in human adults with type 2 diabetes differs from nondiabetic adults. PLoS One 2010, 5:e9085.

46. Willing B, Halfvarson J, Dicksved J, Rosenquist M, Järnerot $G$, Engstrand L, Tysk C, Jansson JK: Twin studies reveal specific imbalances in the mucosa-associated microbiota of patients with ileal Crohn's disease. Inflamm Bowel Dis 2009, 15:653-660

47. Armougom F, Henry M, Vialettes B, Raccah D, Raoult D: Monitoring bacterial community of human gut microbiota reveals an increase in Lactobacillus in obese patients and methanogens in anorexic patients. PLoS One 2009, 4:e7125.

48. Philippe D, Favre L, Foata F, Adolfsson O, Perruisseau-Carrier G, Vidal K, Reuteler G, Dayer-Schneider J, Mueller C, Blum S: Bifidobacterium lactis attenuates onset of inflammation in a murine model of colitis. World J Gastroenterol 2011, 17:459-469.

49. Cani PD, Possemiers S, Van de Wiele T, Guiot Y, Everard A, Rottier O, Geurts L, Naslain D, Neyrinck A, Lambert DM, Muccioli GG, Delzenne NM: Changes in gut microbiota control inflammation in obese mice through a mechanism involving GLP-2-driven improvement of gut permeability. Gut 2009, 58:1091-1103.

50. Tzounis X, Rodriguez-Mateos A, Vulevic J, Gibson GR, Kwik-Uribe C, Spencer JP: Prebiotic evaluation of cocoa-derived flavanols in healthy humans by using a randomized, controlled, double-blind, crossover intervention study. Am J Clin Nutr 2011, 93:62-72.

51. Barcenilla A, Pryde SE, Martin JC, Duncan SH, Stewart CS, Henderson C, Flint HJ: Phylogenetic relationships of butyrate-producing bacteria from the human gut. Appl Environ Microbiol 2000, 6:1654-1661

52. Burger-van Paassen N, Vincent A, Puiman PJ, van der Sluis M, Bouma J, Boehm G, van Goudoever JB, van Seuningen I, Renes IB: The regulation of intestinal mucin MUC2 expression by short-chain fatty acids: implications for epithelial protection. Biochem J 2009, 420:211-219.

53. Lewis K, Lutgendorff F, Phan V, Soderholm JD, Sherman PM, McKay DM: Enhanced translocation of bacteria across metabolically stressed epithelia is reduced by butyrate. Inflamm Bowel Dis 2010, 16:1138-1148.

54. Peng LY, Li Z, Green RS, Holzman IR, Lin J: Butyrate enhances the intestinal barrier by facilitating tight junction assembly via activation of AMP-activated protein kinase in Caco-2 cell monolayers. J Nutr 2009, 139:1619-1625.

55. Wright DP, Knight CG, Parker SG, Christie DL, Roberton AM: Cloning of a mucin-desulfating sulfatase gene from Prevotella strain RS2 and its expression using a Bacteroides recombinant system. J Bacteriol 2000, 182:3002-3007

56. Lin HV, Frassetto A, Kowalik EJ Jr, Nawrocki AR, Lu MM, Kosinski JR, Hubert JA, Szeto D, Yao X, Forrest G, Marsh DJ: Butyrate and propionate protect against diet-induced obesity and regulate gut hormones via free fatty acid receptor 3-independent mechanisms. PLoS One 2012, 7:e35240.

57. Huml M, Kobr J, Siala K, Varvařovská J, Pomahačová R, Karlíková M, Sýkora J: Gut peptide hormones and pediatric type 1 diabetes mellitus. Physiol Res 2011, 60:647-658.

Pre-publication history

The pre-publication history for this paper can be accessed here: http://www.biomedcentral.com/1741-7015/11/46/prepub

doi:10.1186/1741-7015-11-46

Cite this article as: Murri et al: Gut microbiota in children with type 1 diabetes differs from that in healthy children: a case-control study. BMC Medicine 2013 11:46.

\section{Submit your next manuscript to BioMed Central and take full advantage of:}

- Convenient online submission

- Thorough peer review

- No space constraints or color figure charges

- Immediate publication on acceptance

- Inclusion in PubMed, CAS, Scopus and Google Scholar

- Research which is freely available for redistribution

Submit your manuscript at www.biomedcentral.com/submit 